\section{FEVER IN THE CHILD COMING FROM THE TROPICS 15 YEARS EXPERIENCE}

David Torres-Fernández ${ }^{1}$, Ana Pérez de Ayala ${ }^{2}$, Elisa Fernández Cooke ${ }^{1}$, Daniel Blázquez Gamero ${ }^{1}$, Pablo Rojo Conejo ${ }^{1}$, Cinta Moraleda Redecilla ${ }^{1}$, Luis Manuel Prieto Tato ${ }^{1}$, Isabel Fradejas Villajos ${ }^{2}$, Alfredo Pérez Rivilla², Cristina Epalza lbarrondo'.

${ }_{1}^{1}$ Paediatric Infectious Diseases Unit, Hospital Universitario 12 de Octubre (Madrid, Spain)

${ }^{2}$ Microbiology Department, Hospital Universitario 12 de Octubre (Madrid, Spain).

\section{ESP18-0507}

\section{Hospital Universitario Saludimadid 12 de Octubre}

\section{INTRODUCTION}

International travels have grown significantly over last years, as well as imported diseases from tropical areas. Information about paediatric age is scarce.

Our objective is to describe the demographic and clinical characteristics of febrile children coming from the tropics.

\section{METHODS}

Retrospective review of patients $<18$ years old presenting at a tertiary hospital and surrounding primary health care centers with stay in a tropical region during the last year between July 2002 and July 2017.

Patients were selected from microbiological charts of thick smears for malaria and dengue serologies.

\section{RESULTS}

- Total $n: 162$ patients.

- Born in Spain: 49,4\%

- Mean age: 3,5 years-old

(p25 1,4- p75 8,0)

- Pre-travel consultation: $18 \%$

- Complete chemophylaxis: 7,4\%

- First consulted service:

- 81,9\% Emergency Room

- 19,1\% Primary Care Health Centre

\section{MOST FREQUENT DIAGNOSES}

10 Malaria (37 patiens, 22\%)

20 Upper respiratory tract infection

(17 patients, 10,5\%)

3o Viral gastroenteritis (10 patients, 6,2\%)

\section{Destination/Origin area (\%)}

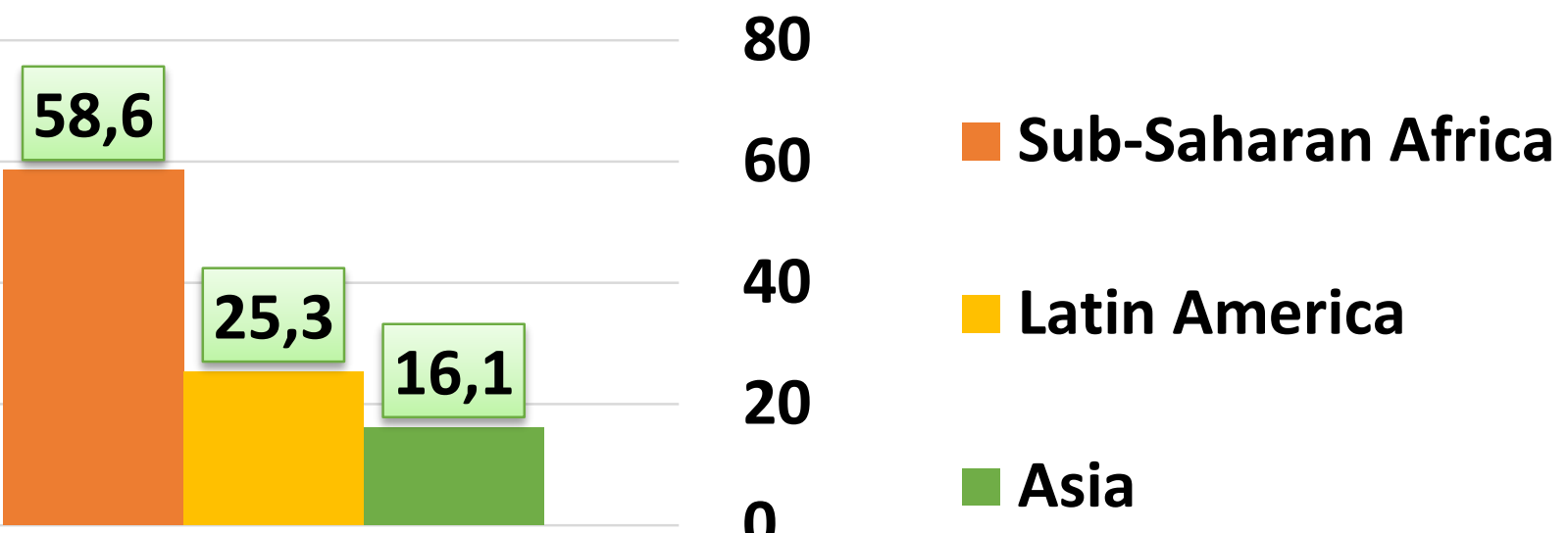

Reason for travelling (\%)

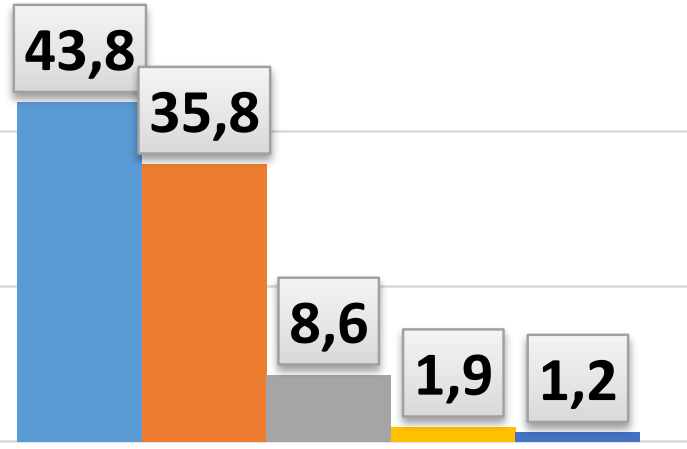

\section{CLINICAL MANAGEMENT}

- 52\% Outpatient management

- 40\% Admitted to paediatric ward

- 6,8\% Paediatric Intensive Care Unit

\section{CONCLUSIONS}

- Nearly a quarter of the febrile children coming from the topics had malaria.

- 7\% of the patients were admitted to Intensive Care Unit.

- $1^{\text {st }}$ consulted place was Emercengy Room for more than $80 \%$ of the patients while the rest went to Primary Care Health Centre.

- Less than one out of five patients attented to a pre-travel consultation. 